\title{
PRINCIPAIS DEFEITOS DE QUEIJOS MINAS ARTESANAIS FABRICADOS NA REGIÃO DA CANASTRA
}

\section{Major defects in artisanal Minas cheeses manufactured in the Canastra region}

\author{
Denise Sobral ${ }^{*}$, Renata Golin Bueno Costa ${ }^{l}$, Junio César Jacinto de Paula ${ }^{1}$, \\ Vanessa Aglaê Martins Teodoro², Gisela de Magalhães Machado Moreiral, \\ Maximiliano Soares Pinto ${ }^{3}$
}

\begin{abstract}
RESUMO
Este estudo foi realizado em 24 propriedades produtoras de queijo Minas artesanal da região da Canastra. Por meio de um questionário, buscou-se conhecer os principais problemas encontrados na fabricação dos queijos artesanais dessa região para proposição de soluções. O volume médio diário de leite para a produção de queijo Minas artesanal nas queijarias foi de 360 litros. A produção de queijo obteve média de 36 peças de 1 quilo por dia. Considerando o volume de leite e a quantidade de queijo produzida por dia, o rendimento médio foi de $10 \mathrm{~L} / \mathrm{kg}$. Os principais defeitos de casca relatados foram: casca grossa, mofada (mofo escuro), casca trincada, coloração desigual (partes mais amarelas que outras), trincas e manchas brancas. Em relação ao sabor foram relatados sabores de ranço, ardido e gostos amargo e (ácido) azedo. O gosto azedo relatado pelos produtores foi relacionado ao estufamento precoce com formação de gás, defeito descrito em 19 dos 24 questionários aplicados. Soluções para os principais defeitos encontrados foram propostas e descritas neste artigo. Verificouse que grande parte dos produtores não seguia o período mínimo de maturação de 22 dias, exigidos pela legislação, comercializando o queijo ainda fresco.

Palavras-chave: estufamento, ranço, gás, contaminação.
\end{abstract}

1 Empresa de Pesquisa Agropecuária de Minas Gerais (EPAMIG), Instituto de Laticínios Cândido Tostes, Rua Tenente Luiz de Freitas, 116, bairro Santa Terezinha, 36045-560, Juiz de Fora, MG, Brasil. E-mail: denisesobral@epamig.br

2 Universidade Federal de Juiz de Fora (UFJF), Juiz de Fora, MG, Brasil.

3 Universidade Federal de Minas Gerais (UFMG), Montes Claros, MG, Brasil.

* Autor para correspondência. 


\begin{abstract}
This study was carried out in 24 cheese farms of artisanal Minas cheese in Canastra region. Using a questionnaire, it was aimed to know the main problems foundin the artisanal Minas cheeses in this region, so that solutions could be proposed. The average daily volume of milk for the production of Artisanal Minas cheese in the cheese farms was 360 liters, and the average production of cheese was 36 pieces of 1 kilo per day. Taking into account the volume of milk and the quantity of cheese produced per day, the average yield was $10 \mathrm{~L} / \mathrm{kg}$. The rind main defects reported were: coarse rind, mold presence (dark or black mold), cracked rind, different colors (parts more yellow than others), cracks and white spots. Concerning flavor aspects, it was reportedrancid flavor, blazing, bitter and sour tastes. The sour taste reported by the producers was related to early blowing with gas formation, a defect described in 19 of the 24 questionnaires applied. Solutions to the major defects reported have been proposed and described in this article. It has also been verified that most of the cheese producers did not follow the minimum maturation period of 22 days required by de legislation and marketed the cheese still fresh.
\end{abstract}

Keywords: blowing, rancidity, gas, contamination.

\section{INTRODUÇ̃̃O}

Minas Gerais possui séculos de tradição nas práticas de fabricar e de comercializar queijos, bem como de consumi-lo como hábito alimentar indispensável à dieta da população. O preparo especial e a aceitação do queijo Minas artesanal estão entrelaçados com a própria identidade do estado, além de manter a sobrevivência de várias famílias, fundamentando a economia de municípios e regiões (EMATER, 2003; MENESES, 2009).

A cadeia de queijos artesanais deve ser ressaltada em virtude de sua grande importância social no processo de manutenção do homem no campo. A existência destes produtos é consequência de seu ambiente histórico e cultural, que devem ser preservados. A produção artesanal de queijos em Minas Gerais, realizada em fazendas e sítios, se perpetuou, passando de geração em geração e assim manteve uma tradição secular que transformou o queijo mineiro num produto reconhecido nacionalmente e internacionalmente (RIBEIRO, 1989).
A Serra da Canastra abrange uma área de $6.453 \mathrm{~km}^{2}$ e localiza-se no sudoeste de Minas Gerais, em uma posição privilegiada, próxima a grandes centros consumidores (EMATER, 2004). A microrregião da Canastra, caracterizada como região produtora de queijo Minas artesanal, é composta pelos municípios de Bambuí, Medeiros, Piumhi, São Roque de Minas, Tapiraí, Vargem Bonita e Delfinópolis. São 1.529 produtores que produzem 5.787 toneladas por ano, gerando 4.281 empregos diretos. O principal produtor deste queijo é o município de São Roque de Minas, onde nasce o rio São Francisco (EMATER, 2004).

Nos queijos artesanais podem surgir defeitos que alteram sua qualidade e segurança e também aqueles que comprometem o rendimento. Além dos defeitos relacionados à contaminação do leite por bactérias, fungos filamentosos e leveduras, podem haver problemas de leite proveniente de vacas com mastite, presença de antibióticos, problemas de coagulação e de leite ácido que afetam a qualidade do queijo (FURTADO, 2017). 
Também existem os problemas relacionados à fermentação que incluem o estufamento tardio e o estufamento precoce ou mesmo a presença de bactérias propiônicas desejáveis ou não. Existem os problemas de alteração de sabor, onde o mais comum é o gosto amargo e o ranço, sendo que a rancidez pode ser espontânea, induzida e microbiana. Além disso, podem ocorrer problemas de textura, de manchas, descoloração, presença de fungos e ácaros, dentre outros (FURTADO, 2017).

Quando há perfeita interação em toda a cadeia de produção do leite, os derivados como o queijo têm maior chance de obter qualidade superior. $\mathrm{O}$ cuidado na fabricação de queijo, além de agregar mais valor ao produto, beneficia os consumidores que passam a ter acesso a um produto mais nutritivo e seguro, com aroma e sabor agradáveis e validade estendida. Para os produtores de queijo a vantagem está no aumento da demanda pelo produto devido à maior qualidade, resultando em melhores preços e lucro.

Sendo assim, o objetivo deste trabalho foi conhecer melhor os problemas enfrentados pelos produtores de queijo Minas artesanal na região da Canastra, por meio da aplicação de questionários, além de propor soluções para os defeitos mais frequentes.

\section{MATERIAL E MÉTODOS}

Após reunião com a EMATER do município de Medeiros, foram selecionadas 24 propriedades rurais dedicadas à produção

\section{Queijo Minas Artesanal da Canastra - MG - Roteiro de entrevistas}

\section{CARACTERÍSTICAS DA QUEIJARIA}

a) Quantos litros de leite por dia?

b) Quantos queijos são produzidos por dia

\section{PROBLEMAS ENCONTRADOS NA FABRICAÇÃO DO QUEIJO}

1) Em geral, o que você gostaria de melhorar no seu queijo?

2) Qual o tempo médio de maturação?

3) A casca do queijo está do jeito que você gostaria? Se não, o que gostaria de melhorar?

4) A casca do queijo é tratada? Qual tratamento?

5) Quais os principais problemas encontrados na fabricação de queijos?

6) Existem problemas diferentes quando muda a estação do ano (época das águas/seca)? Quais?

7) Quais os principais problemas encontrados na maturação?

8) Principais problemas de sabor e odor? Descrever.

9) Principais problemas de aparência? Descrever.

10) Existe algum comentário que gostaria de fazer ou algum defeito que acontece no queijo que não se encaixa nas perguntas acima?

Figura 1 - Modelo de questionário não estruturado aplicado aos produtores de queijos Minas artesanal da região da Canastra 
de queijo Minas artesanal da região da $\mathrm{Ca}$ nastra para aplicação do questionário. As propriedades escolhidas para a pesquisa não necessariamente eram cadastradas no programa Queijo Minas Artesanal do IMA.

O questionário, que se encontra resumido na Figura 1, foi aplicado no período de dezembro de 2016 a janeiro de 2017.

O questionário aplicado aos produtores não foi estruturado e incluiu questões que abordavam a fabricação e a maturação do queijo, além dos principais problemas encontrados. As respostas obtidas no questionário foram analisadas e os principais defeitos relacionados foram tabulados e estudados para que medidas prevenção e correção fossem sugeridas.

\section{RESULTADOS E DISCUSSÃO}

Questões relativas ao volume de produção de leite, número de queijos produzidos e período de maturação

Dos 24 questionários preenchidos, apenas em um não foi respondido sobre o volume de leite coletado por dia e o número de queijos produzidos. De acordo com a Tabela 1, o maior volume registrado foi de 700 litros diários e a maior produção de queijo foi de 80 peças. O menor volume de leite produzido foi de 30 litros diários, com produção de apenas três peças de queijo (Tabela 1). As peças de queijos possuíam um peso médio de 1 quilo para todas as propriedades avaliadas.

De acordo com os resultados expostos na Tabela 1, verificou-se que não havia um volume de produção padrão para a produção de queijos artesanais da região da Canastra e o rendimento médio foi de $10 \mathrm{~L} / \mathrm{kg}$.

Tabela 1 - Informações referentes ao volume de produção

\begin{tabular}{lccc}
\hline & $\begin{array}{c}\text { Valor máximo } \\
(\mathrm{n}=23)\end{array}$ & $\begin{array}{c}\text { Valor mínimo } \\
(\mathrm{n}=23)\end{array}$ & $\begin{array}{c}\text { Média dos resultados } \\
(\mathrm{n}=23)\end{array}$ \\
\hline $\begin{array}{l}\text { Volume de leite captado por dia } \\
\begin{array}{l}\text { Quantidade de queijos } \\
\text { produzidos (números de peças) }\end{array}\end{array}$ & $800 \mathrm{~L}$ & $30 \mathrm{~L}$ & $360 \mathrm{~L}$ \\
\hline
\end{tabular}

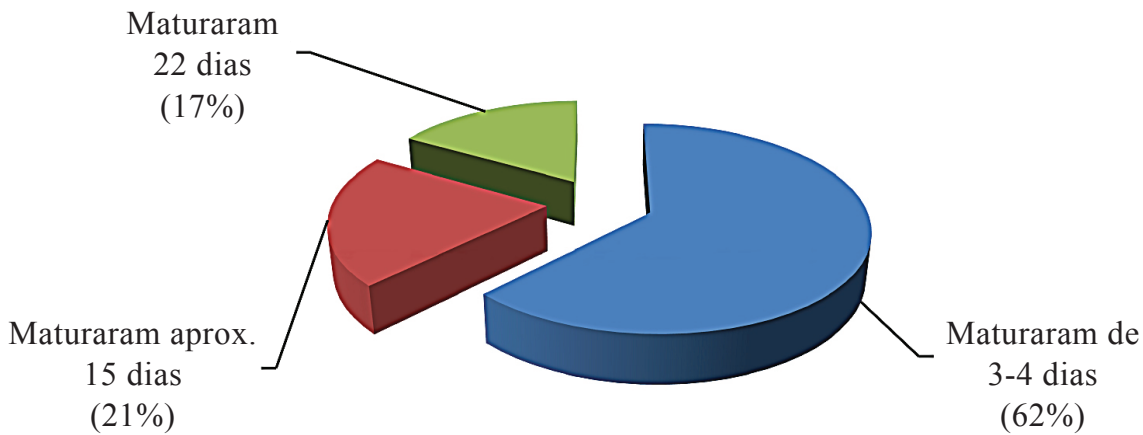

Figura 2 - Frequência do tempo de maturação utilizado pelos produtores entrevistados 
Com relação à maturação dos queijos, a maioria dos produtores não realizava esta etapa e comercializava o queijo fresco, com aproximadamente 3 a 4 dias depois de fabricado (Figura 2).

Em um estudo realizado por Dores (2007), com queijo Minas artesanal fabricado na região da Canastra, foi comprovado que a maturação à temperatura ambiente por 22 dias reduziu a contagem de microrganismos patogênicos dos queijos, tornando-os seguros para o consumo. Sendo assim, com base neste estudo, em 2013 foi aprovada a Portaria $n^{\circ} 1305$ (MINAS GERAIS, 2013), que definiu um período mínimo de maturação de 22 dias para o queijo Minas artesanal fabricado na região da Canastra.

No presente estudo verificou-se que apenas quatro produtores (17\%) maturam o queijo pelo período exigido por lei. A maior parte dos entrevistados respondeu que comercializavam o queijo fresco e que só o maturavam (por aproximadamente 15 dias) quando o queijo era enviado para participar de concursos. Tal resultado pode ter ocorrido devido aos produtores não participarem do programa Queijo Minas Artesanal e não serem cadastrados pelo IMA e não possuírem nenhuma certificação. Como esta pergunta não fazia parte do questionário, não foi possível relacionar a falta de maturação do queijo ao cadastramento ou não da queijaria.

\section{Questões relativas aos defeitos}

\section{Defeitos de casca/aparência}

A superfície do queijo artesanal, quando maturado, necessita de cuidados especiais para que não apareçam defeitos de manchas, rachaduras e contaminação. Alguns produtores relataram que tratam a superfície do queijo com lavagens, outros lixam a casca para dar acabamento e outros não fazem nenhum tratamento, visto que grande parte dos produtores não matura o queijo e não há tempo para a formação de casca.

Alguns lavam a casca diariamente, outros lavam dia sim e dia não e outros lavam de 3 em 3 dias. Um produtor relatou que lava a casca com o próprio soro e disse que este procedimento faz com que o queijo fique mais amarelado e mais homogêneo.

Os principais defeitos de casca relatados foram: casca grossa, mofada (mofo escuro), casca trincada, cores desiguais (partes mais amarelas que outras), trincas e manchas brancas.

Uma variedade de manchas coloridas pode ser observada na superfície dos queijos devido ao crescimento de diferentes microrganismos (Figura 3A). Em geral, a contaminação acontece na elaboração ou na cura, no entanto, no caso dos queijos artesanais, por serem fabricados com leite cru, a contaminação também pode vir do leite (O APARECIMENTO..., 1995). A principal forma de se controlar o aparecimento de manchas na casca dos queijos por contaminação é a higiene na obtenção do leite e aplicação das Boas Práticas de Fabricação (BPF) em todas as etapas, principalmente na maturação. Também não se deve deixar as portas e janelas da queijaria abertas por muito tempo, evitar o manuseio excessivo dos queijos, controlar as características físico-químicas dos queijos como excesso de umidade, $\mathrm{pH}$ anormal e a falta de sal. Ainda é preciso controlar a qualidade da água da queijaria e verificar, por meio de análises microbiológicas, se ela não constitui uma fonte de contaminação (O APARECIMENTO..., 1995).

Outro fator que causa manchas amarelas (Figura 3B) na superfície dos queijos é a falta de viragens regulares e a presença de corredores de circulação de ar nas prateleiras das câmaras de maturação que desidratam desigualmente a superfície do queijo, ficando com alguns pontos mais amarelados que outros (FURTADO, 2017). 
A presença de trincas na casca dos queijos também foi relatada pelos produtores e pode estar relacionada à falta de cálcio na massa, devido à desmineralização durante a fabricação (Figura 4). Quanto maior a produção de ácido lático, maior a retirada de cálcio do complexo de caseína e, mais curta, menos coesa ou mais quebradiça será a massa. A desmineralização é inerente ao processo e ocorre em todo tipo de fabricação de queijo. Um queijo Emmental com $\mathrm{pH}$ de cerca de 5,60 , por exemplo, contém pelo menos $50 \%$ a mais de cálcio que um Cheddar com $\mathrm{pH}$ de aproximadamente 5,10 (TEXTURA DA..., 2002).

Um dos produtores relatou que o problema de trinca ocorre com mais frequência na época da seca. A desmineralização excessiva pode ocorrer quando o queijo possui maior teor de umidade, quando se utiliza pingo em excesso eo queijo tende a fermentar mais e produzir mais acidez. Isto resulta em maior desmineralização, deixando a massa mais quebradiça, frágil e suceptível à formação de trincas (TEXTURA DA..., 2002). Queijos muito secos, com baixa umidade ou que perderam muita umidade para o ambiente (no caso de queijos maturados em câmaras muito secas) também podem ser suceptíveis ao defeito de trincas. Para evitar o problema, deve-se manter a umidade relativa do ar (URA) adequada para cada tipo de queijo (média a $85 \%$ URA para a maioria dos queijos). Também é necessário o controle das
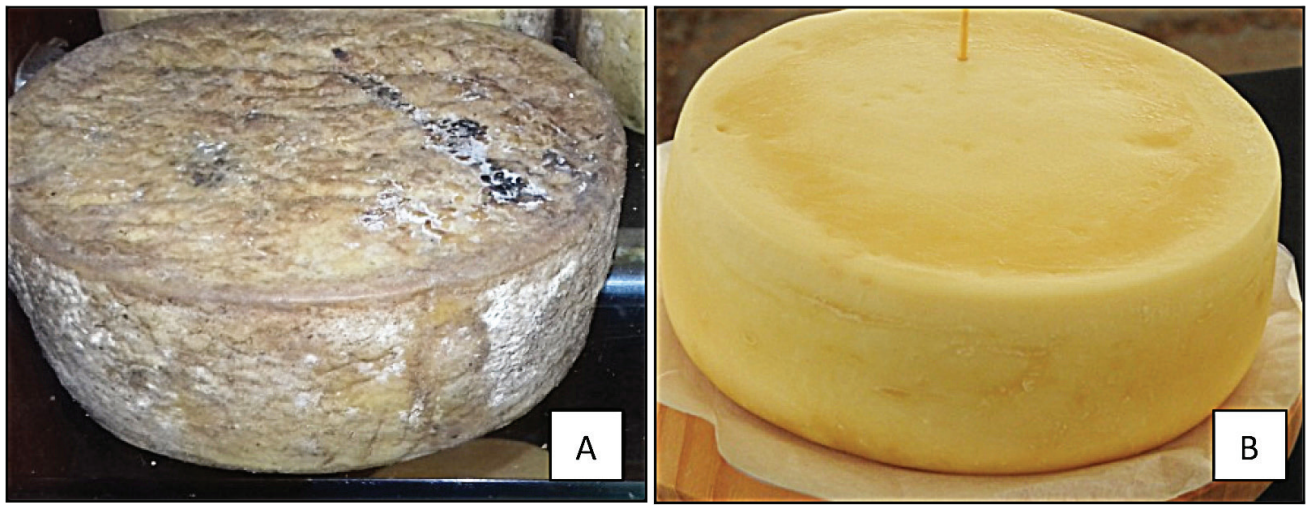

Figura 3 - Queijo artesanal apresentando manchas por contaminação (A) e queijo artesanal apresentando manchas amarelas (B)

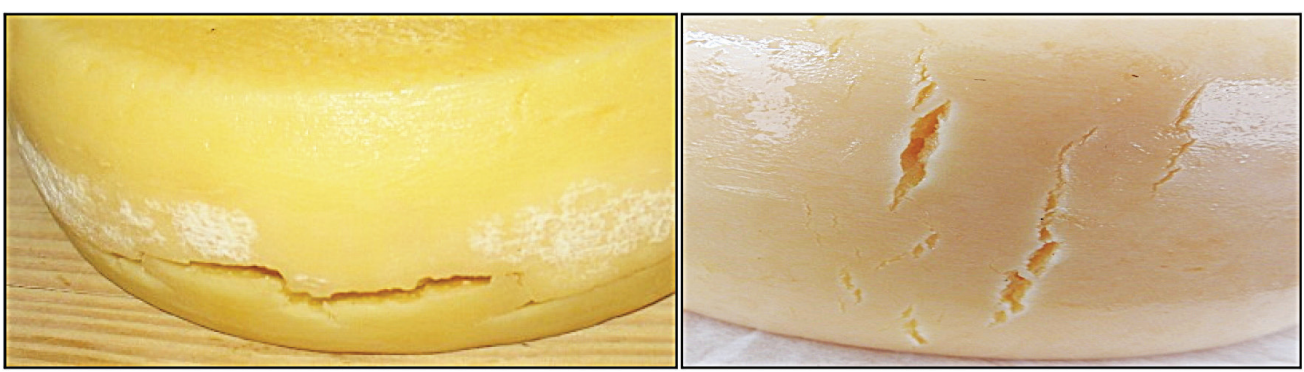

Figura 4 - Queijos com problemas de trincas na casca 
correntes de ar dentro da câmara de maturação para evitar a formação de trincas em lotes específicos, mantidos próximos à ventilação excessiva.

Outro fator que contribui para a formação de trincas na casca é o excesso de lavagens da superfície do queijo, como naqueles em que ocorre o crescimento indesejável de mofos na superfície. Sucessivas lavagens podem fazer com que a casca do queijo fique cada vez menos elástica e mais propensa a trincar.

\section{Queijos com estufamento tardio ou precoce}

A maioria dos produtores possui problemas com estufamento precoce, visto que não realizam a maturação e não há tempo do estufamento tardio ocorrer no queijo. Dos 24 questionários aplicados, 19 relataram problemas de estufamento precoce que é chamado pelos produtores de queijo inchado (Figura 5). Muitos deles também relataram que quando o queijo incha, o gosto do queijo fica diferente, descrevendo este defeito de sabor como azedo, amargo e ardido. Alguns produtores relataram desconhecer a causa do aparecimento do defeito.

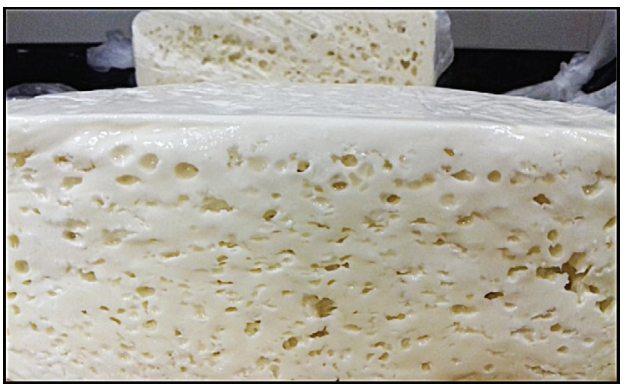

Figura 5 - Queijos aparência típica do defeito estufamento precoce, relatado pelos produtores como queijo inchado

O estufamento precoce é o processo fermentativo indesejável das bactérias do grupo coliforme ou de leveduras que fermentam a lactose com produção de gás. Neste processo, são formadas pequenas e numerosas olhaduras indesejáveis nos queijos, comprometendo sua aparência e o seu sabor (McSWEENEY, 2007).

Algumas bactérias do grupo coliforme são indicadoras de contaminação fecal e, se as contagens são altas, podem indicar a presença potencial de agentes patogênicos. Este defeito é chamado estufamento precoce, pois aparece nas primeiras horas da fabricação do queijo, muitas vezes ainda no tanque de fabricação ou na salga (McSWEENEY, 2007).

Os principais compostos produzidos por coliformessão: ácido lático, ácido acético, etanol, $\mathrm{CO}_{2}, \mathrm{H}_{2}$. A produção de gás começa a se tornar visível quando a contagem de microrganismos atinge valores de aproximadamente 100 a 400 coliformes/g de queijo (McSWEENEY, 2007). Nos queijos artesanais, como não existe a etapa de pasteurização do leite, este defeito pode ocorrer com mais frequência.

A contaminação do leite e do queijo por estes microrganismos pode ter origem na falta de higiene do ordenhador ou da pessoa responsável por fabricar o queijo (visto que os queijos artesanais são muito manipulados), nas más condições de limpeza e sanitização das instalações e equipamentos, e na utilização de água contaminada, ou seja, condições precárias de higiene praticadas nas diferentes fases de obtenção do leite, fabricação e comercialização do queijo (McSWEENEY, 2007). É importante ressaltar que quando este defeito surge, não é possível utilizar o pingo para a produção do dia seguinte.

O estufamento tardio manifesta-se nos queijos pela presença de trincas internas, podendo apresentar áreas descoradas e macias, odor e sabor anormais, principalmente sabor de ranço. Estas alterações são resultantes do processo fermentativo indesejável, por meio da fermentação do lactato e da glicose presentes no queijo, por bactérias do gênero Clostridium spp, principalmente as espécies 
Clostridium tyrobutyricum, $C$. butyricum e $C$. sporogenes. A partir do lactato são formados os compostos: ácido butírico, ácido acético, $\mathrm{CO}_{2}, \mathrm{H}_{2}$, enquanto da glicose são formados: ácido acético, ácido butírico, etanol, butanol, acetona, $\mathrm{CO}_{2}, \mathrm{H}_{2}$ (BRÄNDLEet al., 2016).

O defeito é chamado estufamento tardio, pois demora um tempo maior para se manifestar em relação ao estufamento precoce, ou seja, se manifesta no período de 10 dias até oito semanas após a fabricação do queijo, podendo aparecer na câmara de maturação, no ponto de venda ou na casa do consumidor (BRÄNDLE et al., 2016).

Para evitar este defeito nos queijos deve-se utilizar leite de boa qualidade microbiológica, uma vez que boa parte dos esporos de Clostridium spp. são provenientes do solo, da poeira e do ambiente em geral. Um dos procedimentos adotados para reduzir a contagem bacteriana e o número de esporos de clostrídios no queijo é não utilizar o leite das vacas alimentadas com silagem para a fabricação desses queijos. No entanto, muitas vezes a contaminação não pode ser completamente evitada. Queijos com baixo teor de sal, menor teor de umidade e com a casca mais firme são mais susceptíveis ao surgimento de estufamento tardio. Queijos embalados a vácuo e com embalagens plásticas impermeáveis e queijos com $\mathrm{pH}$ mais elevado também possuem maior probabilidade de apresentarem este defeito (BRÄNDLE et al., 2016).

\section{Queijos com defeitos de sabor}

Os defeitos de sabor relatados nos questionários se encontram na Tabela 2 .

$\mathrm{O}$ defeito mais frequente foi sabor azedo devido ao estufamento precoce. Como este defeito é causado por problemas de fermentação de bactérias láticas e também do grupo coliforme, alguns compostos podem causar sabor e odor indesejáveis muitas vezes descritos como sabor azedo, ardido ou de ranço. As soluções para este tipo de problema já foram relatadas no tópico anterior e está relacionada às condições de higiene de todo o processo, inclusive a ordenha, para evitar as contaminações.

Tabela 2 - Defeitos relacionados ao sabor relatados pelos produtores

\begin{tabular}{lc}
\hline $\begin{array}{c}\text { Tipo } \\
\text { de } \\
\text { defeito }\end{array}$ & $\begin{array}{c}\text { Número de } \\
\text { vezes relatado } \\
(\mathrm{n}=24)\end{array}$ \\
\hline Gosto amargo & 5 \\
Sabor de ranço & 1 \\
Sem sabor & 1 \\
Gosto ácido/ azedo & 12 \\
Sabor ardido & 1 \\
\hline
\end{tabular}

O gosto amargo, segundo defeito mais relatado, acontece com maior frequência em queijos maturados, pois surge devido a uma maturação (proteólise) descontrolada, mas pode surgir em queijos frescos ou com poucos dias de maturação. Na maior parte dos casos, este defeito é resultado do acúmulo de peptídeos hidrofóbicose amargos, formados devido a uma proteólise primária e secundária desequilibrada (FALLICO et al., 2005). Este desequilíbrio pode surgir devido a motivos diversos e, por isso, é um dos mais difíceis de resolver e de identificar o agente causador (O GOSTO..., 1992).

A escolha do tipo de coalho/coagulante e a dose utilizada são importantes para evitar este defeito, pois coalhos com maior proporção de pepsina, muito utilizados na produção dos queijos artesanais, tendem a causar o gosto amargo, devido à formação de peptídeos amargos pela ação inespecífica dessa enzima. Doses de coalho acima das recomendadas pelo fabricante também podem provocar o amargor, devido ao maior acúmulo da enzima na massa de queijo. O ideal é utilizar a dose de coalho/coagulante recomendada pelo fabricante. Além disso, o leite com acidez mais elevada, retém mais 
coagulante na massa, o que pode aumentar a chance de amargor no queijo (PAULA et al., 2017). Também é importante manter os teores de umidade e sal do queijo padronizados e sem excessos (nem muito elevados e nem muito baixos) para que o defeito não apareça (FALLICO et al., 2005).

\section{O que os produtores gostariam de melhorar no queijo}

Os produtores foram questionados em relação ao que gostariam de melhorar de uma maneira geral no queijo produzido por eles. Os itens mais comentados foram a aparência e a qualidade (Figura 6).

Dois produtores relataram que não precisam melhorar o queijo, pois as alterações não agregam valor ao produto e, por isso, não se sentem motivados para investir na qualidade. Outros dois produtores responderam que estão satisfeitos com o queijo que produzem e, assim, não necessitam de melhorias.

\section{Outros problemas}

Alguns produtores citaram gargalos na produção, que não envolviam diretamente o queijo, mas que podem influenciar sua qualidade. Dentre esses problemas podemos citar: a disponibilidade de mão de obra para contratação, a falta de tempo, o custo elevado de produção, a legislação incoerente, a falta de tratamento de esgoto, o controle da mastite, as variações com as estações do ano e as mudanças climáticas.

Estes relatos indicam que muitos estudos ainda podem ser realizados na produção do queijo Minas artesanal, com a finalidade de melhorar e descobrir o porquê de tais dificuldades. Além disso, são necessários mais investimentos por parte do governo para melhorar a assistência técnica ao produtor, a educação para a produção com qualidade, a formação de mão de obra qualificada, dentre outras medidas.

\section{CONCLUSÕES}

O queijo Minas artesanal da região da Canastra é produzido há séculos e a tecnologia utilizada é repassada de geração em geração. No entanto, com a valorização deste produto no mercado e também pelos consumidores que apreciam pratos diferenciados na gastronomia que utilizam esta iguaria, o queijo Minas artesanal vem conquistando lugar de destaque, sendo cada vez mais consumido. Para atender a este novo mercado cada vez mais exigente, os produtores de queijos artesanais precisam melhorar a qualidade do produto oferecido e, com isso, aumentar sua renda. Neste contexto o estudo dos defeitos mais recorrentes foi importante para elucidar e solucionar alguns

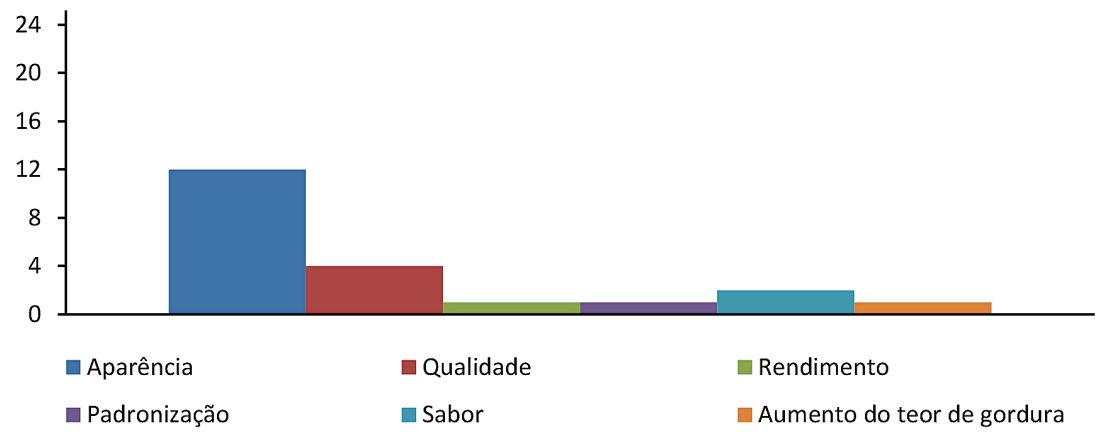

Figura 6 - Respostas mais frequentes do que os produtores gostariam de melhorar no queijo 
dos problemas mais frequentes encontrados e relatados pelos produtores. Os defeitos em queijo Minas artesanal é um assunto extenso que ainda deve ser discutido em estudos futuros, para que o queijo seja valorizado, assim como a mão de obra dos pequenos produtores.

\section{AGRADECIMENTOS}

À FAPEMIG, pelo financiamento da pesquisa e concessão das bolsas BIPDT e BIC. À EMATER e aos produtores pelo empenho e disponibilidade em contribuir com esta pesquisa.

\section{REFERÊNCIAS}

BRÄNDLE, J. et al. Relevance and analysis of butyric acid producing clostridia in milk and cheese. Food Control, v. 67, p. 96-113, 2016.

DORES, M. T. Queijos artesanais da Canastra maturado a temperatura ambiente e sob refrigeração. 2007. 106p. Dissertação (Mestrado em Ciência e Tecnologia de Alimentos). Viçosa, MG: UFV, 2007.

EMATER. EMPRESA DE ASSISTENCIA TECNICA E EXTENSAO RURAL DE MINAS GERAIS. Caracterização da Microrregião da Canastra como produtora de Queijo Minas Artesanal. São Roque de Minas. 2004. Disponível em: <http://www. emater.mg.gov.br/doc/intranet/upload / QUEIJO HISTORICO/caracteriza $\% \mathrm{C} 3 \% \mathrm{~A}$ 7\%C3\%A3o\%20do\%20queijo\%20canastra. pdf>. Acesso em: 09 abr. 2012.

EMATER. EMPRESA DE ASSISTENCIA TECNICA E EXTENSAO RURAL DE MINAS GERAIS. Memória da reunião de 10/07/03 - Anexo 1: Programa de apoio aos queijos tradicionais de fabricação artesanal do estado de Minas Gerais, Belo Horizonte - Sede da EMATER. 2003.
FALLICO, V. Evaluation of Bitterness in Ragusano Cheese. Journal of Dairy Science, v. 88 , n. 4, p. $1288-1300,2005$.

FURTADO, M. M. Principais problemas dos queijos. São Paulo: Setembro Editora, 2017. $256 \mathrm{p}$.

MENESES, J. N. C. Modos de fazer e a materialidade da cultura "imaterial": o caso do queijo Minas Artesanal de Minas Gerais. UNESP-FCLAS-CEDAP, v. 5, n. 2, p. 27 41, dez., 2009.

MINAS GERAIS. Instituto Mineiro de Agropecuária (IMA). Portaria $n^{\circ} 1.305$. Estabelece diretrizes para a produção do queijo $\mathrm{Mi}$ nas artesanal. Belo Horizonte, 30 de abril de 2013 .

McSWEENEY, P. L. H. Cheese problems solved. CRC Press: Boca Raton, Boston, New York, Washington, 2007. 425 p.

O APARECIMENTO de manchas em queijos. Ha-LaBiotec, Valinhos, n. 26, mar., 1995.

O GOSTO amargo em queijos. Ha-LaBiotec, Valinhos, n. 9, mai., 1992.

PAULA, J. C. J. de, et al. Gosto amargo em queijo Minas Frescal: possíveis causas e prevenção. Revista Indústria de Laticínios, n. 127 , p. 118-122, 2017.

RIBEIRO, L. M. Produtores rurais de queijos em busca de uma nova realidade. Revista do Instituto de Laticínios Cândido Tostes, Juiz de Fora, v. 44, n. 261-266, p. 86-89, jan./ dez, 1989.

TEXTURA DA massa de queijo: fatores que a influenciam e parâmetros de controle (Parte I). Ha-LaBiotec, Valinhos, ano XI, n. 69, mai./jun., 2002. 